\title{
Application of vacuum solid-phase microextraction for the analysis of semi-hard cheese volatiles
}

\author{
M. Sýkora ${ }^{1}$ E. Vítová ${ }^{1}$ H. H. Jeleñ ${ }^{2}$ (D)
}

Received: 9 June 2019 / Revised: 14 December 2019 / Accepted: 21 December 2019 / Published online: 9 January 2020

(C) The Author(s) 2020

\begin{abstract}
Solid-phase microextraction (SPME) is a well-established technique in the analysis of food volatile compounds, usually performed for qualitative analysis. This paper presents an elaboration of conditions for SPME analysis of main volatile compounds in hard cheese and an evaluation of suitability of vacuum to improve the transfer of volatile compounds towards SPME fiber. Compounds representing the main groups of hard cheese volatiles were investigated: 1-pentanol, butanoic acid, 2,3-butanedione and 2-heptanone. Parameters for SPME extraction (temperature, water, sodium carbonate addition, time, vacuum) were evaluated. Application of vacuum had a positive effect on all analytes when extraction was performed from water, but in the cheese matrix the effect was significant only for butanoic acid. Extraction time was the most significant factor for extraction efficiency in examined cheeses, while temperature had a minor effect on the amount of extracted volatiles. The method was applied on Edam, Emmentaler, Gouda and Maasdam cheeses obtained from the market.
\end{abstract}

Keywords Semi-hard cheese $\cdot$ SPME $\cdot$ Vacuum $\cdot$ GC-MS

\section{Introduction}

Headspace solid-phase microextraction (HS-SPME) is a selective, sensitive and solvent-free sampling technique, which is widely used for the extraction of volatile and semivolatile compounds based on their absorption/adsorption on SPME fiber. The availability of various SPME coatings, depending on the polarity of analytes, provides high selectivity and sensitivity, which arise from the high affinity of the coating to specific analytes that are accumulated in the headspace until equilibrium is reached. Initially, only fibers offering absorption into coating were available (polydimethylsiloxane and polyacrylate) [1]. In the absorption process, compounds diffuse into whole volume of coating, contrary to adsorption which is a surface phenomenon and depends on the character and pore size of used sorbent. The second group of SPME fibers is based usually on carboxene, divinylbenzene, or their combination. These sorbents

\section{H. H. Jeleń}

henrykj@up.poznan.pl

1 Department of Food Science and Biotechnology, Brno University of Technology, 60190 Brno, Czech Republic

2 Faculty of Food Science and Nutrition, Poznań University of Life Sciences, 60-624 Poznań, Poland are mixed with polydimethylsiloxane. In such fibers, adsorption process prevails and usually they are characterized by very low detection limits achieved for analytes, but often have worse linearity than absorption-type fibers. HS-SPME is usually performed as an equilibrium method, when the analyte concentration has reached equilibrium in the threephase system composed of the sample, the headspace and the fibre. However, the achievement of equilibrium is not necessary to complete quantitative/qualitative analyses [2]. The typical combination of gas chromatography-mass spectrometry (GC-MS) provides low cost, relatively simple and effective analyses of volatile compounds. Even though it is not ideal as a method of extraction, HS-SPME analysis has gained wide attention by being robust, less laborious and time consuming, while additionally having other advantages, such as sensitivity and limited risk of artefacts related to the absence of solvents [3, 4].

Various techniques have been used to shorten the sample/ headspace equilibration time in the vial, including agitating the sample, maximizing the sample/headspace interface, heating the sample and using internally cooled SPME fiber to minimize the desorption effect observed in sampling at elevated temperatures [5].

Vacuum has been used in the analysis of volatiles for many years, with high vacuum transfer or related methods 
involving low-pressure distillation being applied in cases requiring minimization of changes within the sample, such as in flavor research in particular [6]. Using vacuum for SPME sampling was first described by Brunton in an analysis of turkey meat volatiles [7]. Recent studies of Psillakis showed that using vacuum with HS-SPME shortened the time of equilibration between the three phases of the system both for volatile and semi-volatile compounds [8]. Reduced pressure conditions of pre-equilibrium HS-SPME sampling for analytes with low headspace affinity have been experimentally verified [9]. Single-port closures, such as Mininert ${ }^{\circledR}$ designed for vacuum headspace solid-phase microextraction (Vac-HS-SPME), made sampling much simpler [10]. Vacuum-assisted extraction methods have been applied for various liquid matrices. For instance, vacuum HS-SPME (Vac-HS-SPME) was used for the analysis of 2-methylisoborneol and geosmin in water [11]. This method was also adopted for the extraction of acids and phenols from milk and milk products [12]. The number of applications is still limited and there is a need to test the use of Vac-HS-SPME for different matrices, including solid ones. For this reason, selected volatiles present in cheese (hard or semi-hard) were the object of our interest.

As one of the commonly consumed cheese, Emmental is a yellow semi-hard Swiss-type cheese with a smooth taste, which is originally produced in the Emmental (Canton Bern, Switzerland). The flavor of cheese comes from the degradation of milk proteins, fat, lactose and citrate because of the enzymatic activities of microorganisms, coagulants and milk itself. A wide range of volatile compounds is involved in cheese flavor including lactones, fatty acids, nitrogen- and sulfur-containing compounds, alcohols, ketones, esters and aldehydes [13-16]. The flavor of Emmental is described as slightly nutty, with the following key odorants identified: 3-methylbutanal, ethyl octanoate, methional, oct-1-en-3one, 2-heptanone, 2,3-butanedione, butanoic acid, 2-methyl butanoic acid, propionic acid, acetic acid, furaneol and 5-ethyl-4-hydroxy-2-methyl-3(2H)-furanone [17-19]. HSSPME was used to investigate cheese volatile and aroma compounds and numerous papers may be found on their profiles in different cheeses [20-23] or changes in ripening and maturation processes [24, 25]. Typically, the following main groups of compounds account for the profile of cheese volatiles: acids, alcohols, esters, ketones and aldehydes, while in some cheeses sulfur compounds or pyrazines play an important role. Ziino et al. in Provola dei Nebrodi, a Sicilian cheese, identified by HS-SPME C2-C12 acids (with C4, C6, C8 and C10 being predominant), esters (mainly ethyl, propyl and butyl esters of the aforementioned acids), ketones, alcohols and aldehydes [26]. Delgado applying SPME identified 64 compounds in goat raw milk cheese (14 acids, 18 alcohols, 13 esters, 6 ketones and 13 other ones), without quantifying them [24]. Surprisingly, compared to the number of papers on profiling volatiles by SPME, the number of those devoted to their quantification is extremely limited. This may be due to the nature of the matrix, which makes it difficult to work using quantitative SPME, where at elevated temperature hard cheeses melt, changing dramatically the release process of volatiles and their partition coefficients. Also, volatiles in cheese are present in highly diverse concentrations, while their abundance and chromatographic features (as for volatile acids) may hinder their analysis. A very detailed work on the quantification of fatty acids in cheese by multiple headspace SPME was published by Rincan et al. [27].

The aim of this work was to test the applicability of vacuum HS-SPME/GC-MS to analyze the main volatile compounds of natural hard cheeses and evaluate if it is beneficial for compounds of different characters that are released from hard cheese. HS-SPME experimental conditions, such as the sample/salt ratio, sample/water ratio, time and temperature of extraction, were optimized in this study. The method was compared with classical ambient pressure SPME and applied on selected samples of natural hard cheeses purchased at a local market. Compounds for method evaluation were selected based on the GC/MS analysis of cheese used as a matrix and compounds representing the main classes were selected.

\section{Materials and methods}

\section{Cheese samples}

Five selected Swiss- and Dutch-type cheeses were analyzed in this work. An Emmental cheese block of $2.5 \mathrm{~kg}$ (56\% dry matter, $27 \%$ fat in dry matter) was used for optimization of the method conditions. Four other cheese blocks were used to validate the method: Swiss-type Emmentaler (55\% dry matter, $26 \%$ fat in dry matter), Dutch-type Edam (53\% dry matter, 26\% fat in dry matter), Dutch-type Gouda (54\% dry matter, $28 \%$ fat in dry matter) and Swiss-style Dutchtype Maasdam (54\% dry matter, $26 \%$ fat in dry matter). All the cheeses were purchased at the local market. Cheeses were cut into cubes, frozen in liquid nitrogen, mechanically ground in a mortar and pestle and stored at $-18{ }^{\circ} \mathrm{C}$ prior to analysis.

\section{Chemicals}

The following standards of volatile compounds were used for optimization and validation of the method: 1-pentanol, butanoic acid, 2,3-butanedione and 2-heptanone. They were all purchased from Sigma-Aldrich (Poznań, Poland) and stored at $4{ }^{\circ} \mathrm{C}$ in a refrigerator. 
Quantification of volatile compounds in cheese samples was performed by calibration using standards (10-1000 ppb) added to the cheese matrix, after subtraction of the peak area of compounds recorded in the matrix without standard addition. Calibration curves for the evaluation of vacuum effect on the behavior of extracted compounds were prepared using water solutions of standards in the concentration range from $1 \mathrm{ppb}$ to $1 \mathrm{ppm}$ and analyzed at the same conditions as the cheese samples.

\section{HS-SPME and vacuum HS-SPME procedures}

The SPME polydimethylsiloxane/divinylbenzene (PDMS/ DVB) fiber with a $65-\mu \mathrm{m}$-thick coating was purchased from Supelco (Bellefonte, PA). The fiber was conditioned before the initial use, as recommended by the manufacturer. The HS sampling procedure was as follows: a cap-sealed (silicon/ PTFE lined alumina cap) $22 \mathrm{ml}$ vial containing the sample was kept at $50{ }^{\circ} \mathrm{C}$ for $10 \mathrm{~min}$ in an aluminum heating block (IKA RCT, Model B). Afterwards, the SPME fiber was exposed to the sample for $30 \mathrm{~min}$ at $50{ }^{\circ} \mathrm{C}$. After sampling, the compounds on the fiber were thermally desorbed in the GC injection port. The sample was cheese or standard compounds in water, depending on the experiment.

For the vacuum experiments prior to the analyses the pressure was lowered at room temperature by removing $20 \mathrm{ml}$ of air from the sealed vial using a $30 \mathrm{cc}$ MICROMATE interchangeable glass syringe from Popper and Sons, Inc. (New York, USA). Unlike at ambient pressure, SPME was used in vacuum sampling Mininert closures, as described in [10]. Because of the nature of the matrix for analyses, cheese was closed in the vial, capped and then air was evacuated with a syringe. Usually for liquid matrices, first the air was evacuated from the vial, then the (liquid) sample was introduced [8].

\section{GC-MS analysis}

GC analysis was performed on a LECO PEGASUS ${ }^{\circledR}$ BT GCTOFMS gas chromatograph (LECO, St. Joseph, MI, USA). The operational oven conditions were: the temperature programmed from $40{ }^{\circ} \mathrm{C}$ (held for $1 \mathrm{~min}$ ) to $220^{\circ} \mathrm{C}$ at $9{ }^{\circ} \mathrm{C} /$ min; from 220 to $280{ }^{\circ} \mathrm{C}$ at $20{ }^{\circ} \mathrm{C} / \mathrm{min}$, held for $5 \mathrm{~min}$. The GC was equipped with a split/splitless injector; the desorption time was $10 \mathrm{~min}$ in the splitless mode at $250{ }^{\circ} \mathrm{C}$ (the purge valve was opened after $1 \mathrm{~min}$.). The injection port was mounted with a standard SPME liner (Supelco, Italy). The carrier gas was helium with a corresponding linear velocity of $35 \mathrm{~cm} / \mathrm{s}$. A non-polar DB-5 capillary column (Agilent Technologies, Santa Clara, California, USA) was used (length of $30 \mathrm{~m}$, a $0.25 \mathrm{~mm}$ diameter and a $0.25 \mu \mathrm{m}$ film).

The following conditions were used for the MS detector: ion source temperature of $200{ }^{\circ} \mathrm{C}$, acquisition range of
TOFMS over an $\mathrm{m} / \mathrm{z}$ range of $40-500$ amu at 50 spectra per sec collection speed.

\section{Method optimization}

To optimize the method, vacuum HS-SPME was performed at different temperatures $\left(40{ }^{\circ} \mathrm{C}, 50{ }^{\circ} \mathrm{C}\right.$ and $\left.60{ }^{\circ} \mathrm{C}\right)$ and for different sorption times ( $5 \mathrm{~min}, 15 \mathrm{~min}, 30 \mathrm{~min}, 45 \mathrm{~min}$ ). The significance of differences was statistically tested by ANOVA.

For the method optimization procedure, the samples were prepared as follows: $1 \mathrm{~g}$ of cheese, $1 \mathrm{~g}$ of cheese with the addition of water $(1 \mathrm{ml})$ and $1 \mathrm{~g}$ of cheese with the addition of saturated $\mathrm{Na}_{2} \mathrm{CO}_{3}(1,2$ or $4 \mathrm{ml})$. All samples were prepared in triplicates in standard $20 \mathrm{ml}$ headspace vials. Cheese samples in the vials were preheated at $50{ }^{\circ} \mathrm{C}$ for 10 min before the SPME fiber was inserted into the vial.

\section{Results and discussion}

The SPME method with the use of vacuum was used to investigate the optimal cheese preparation process (i.e. sample form: analysis of dry cheese vs. slurry with an addition of water or sodium carbonate), the effect of time and temperature for extraction. The optimization of method parameters was performed using compounds naturally present in the cheese (rather than the cheese matrix, spiked with standards).

\section{The effect of sample preparation method on the amount of extracted volatiles}

Cheese samples were prepared in different ways to compare the amounts of volatile compounds released from the matrix in the extraction process. Analyses were performed on powdered cheese alone, powdered cheese with water as a slurry/mixture and powdered cheese with various volumes of a saturated sodium carbonate solution (to lower the fatty acid content). The addition of sodium carbonate was used to lower the free fatty acid contents, to minimize their influence on the other peaks (especially when analyses are performed on the non-polar GC column); this approach was previously used by other authors [28].

The results expressed as the total content of volatile compounds/total peak area are shown in Fig. 1. For each Emmental matrix variant, the total peak area (excluding fatty acids) and separately fatty acids (marked in black) were shown. As can be observed for powdered cheese (which melted at $50{ }^{\circ} \mathrm{C}$, the temperature used for sampling in this experiment), the total peak area was the highest, but also the ratio of free fatty acids to all volatile compounds was the highest among the tested variants. Such high amounts of 


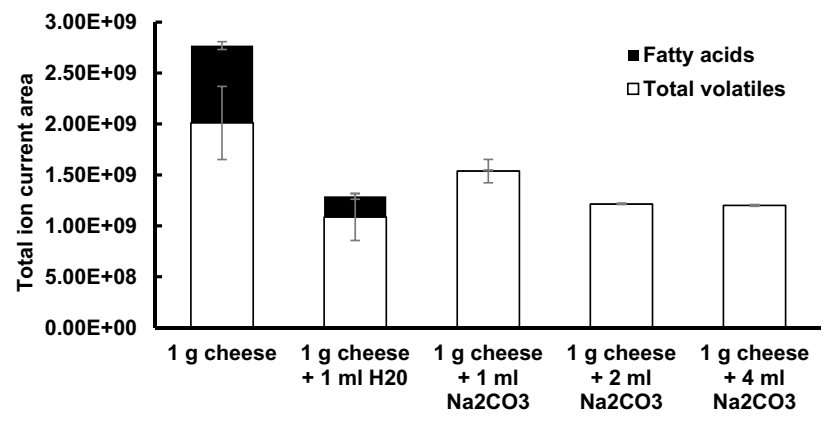

Fig. 1 Influence of Emmental cheese sample preparation methodology on total volatiles and total fatty acids amounts extracted by Vac$\operatorname{HS}-\operatorname{SPME}(n=3)$

volatile fatty acids may have a negative effect on the separation of other compounds and may affect the linearity of SPME extraction, being too high for the fiber capacity, especially when the adsorbent type of fiber is used. The SPME fiber used in the current study was PDMS/DVB. Polymerbased fibers were usually selected by other researchers when profiling volatiles in cheese $[19,27]$. However, a competing phenomenon for butanoic and hexanoic acids was observed for this type of fibers [29] For the other variants, an addition of water also resulted in high levels of free fatty acids, comparable (in the ratio to total volatile compounds) to powdered cheese alone.

As could be expected, in the case of variants involving a sodium bicarbonate solution, the free fatty acids in the headspace were grossly reduced, which facilitates quantitation of the other compounds by SPME. The use of powdered cheese with $1 \mathrm{ml}$ of saturated sodium carbonate solution reduces peak areas of acids, but they remain high enough to facilitate quantitative analysis, given selected fiber as previously described. Further addition of the saturated sodium carbonate solution $(2 \mathrm{ml}$ and $4 \mathrm{ml})$ had no significant $(p<0.05)$ effect on either free fatty acids or total volatile compounds (Fig. 1). In the case of difficulties in quantitation of volatile fatty acids in cheeses, when their amount is much lower, it is advisable to first use a polar column for analysis, while it might be necessary to replace the sodium carbonate addition with water.

\section{The effect of extraction time on isolated compounds}

Volatile compounds in cheese (1-pentanol, butanoic acid, 2,3-butanedione and 2-heptanone) were monitored at different extraction times to investigate the optimum isolation time for alcohols, acids, diketones and ketones. Extraction was performed at $50{ }^{\circ} \mathrm{C}$ with varying extraction times $(5$, $15,30,45 \mathrm{~min})$. The data show that an increased time exposure of the fiber promoted greater sorption of volatile compounds (Fig. 2). A longer exposure of the fiber to the

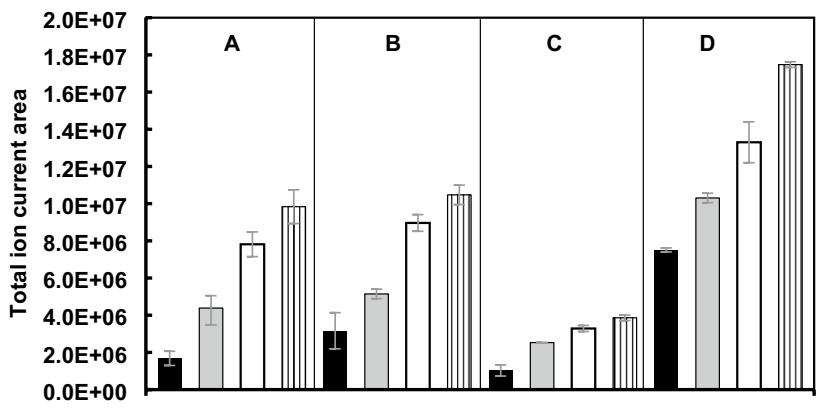

Fig. 2 Distribution of selected volatile compounds for different Vac-HS-SPME extraction times: 5 min (black), 15 min (grey), 30 min (white), 45 min (zebra); A-1-pentanol; B-butanoic acid; C-2,3-butanedione; D-2-heptanone $(n=3)$

headspace enables greater capture of the compounds until saturation if polymer-based fibers are used. Therefore, it is usually advisable to have longer extraction times during analysis to reach the headspace/fiber sorbent equilibrium; however, in SPME extraction the profile of compounds adsorbed on a fiber surface may be highly dependent on extraction time and the nature of the compounds, depending on their partition coefficients in specific phases and volatility, as a competitive effect may occur and extraction of some compounds may favor them over others [30]. The procedure of 30-min exposure, according to the optimal accuracy with time-efficient extraction, was selected for further method optimization steps as a compromise between extraction and analysis time. Frank et al. in their characterization of various cheeses using gas chromatography-olfactometry and gas chromatography-mass spectrometry used extremely long extraction time of $16 \mathrm{~h}$. They observed some displacement phenomena after this long extraction time, which was most notable for cheeses undergoing extensive lipolysis (i.e. pecorino) with high concentrations of butanoic and hexanoic acids. While the comparison was made based on peak areas, rather than quantification, they observed an increase in hexanoic acid contents with a simultaneous decrease of butanoic acid [29]. On the other hand, in analysis of Fiore Sardo Cheese [25] acids, mostly butanoic and hexanoic, were predominant volatiles, being abundant in very short extraction time such as $3 \mathrm{~min}$.

As can be seen in Fig. 3, a longer extraction time had a significant $(p<0.05)$ effect on peak areas, which may be especially important for quantitative analysis. As shown for butanoic acid, calibration curves produced as a result of 15 and 60 min extraction times are considerably different with a marked impact on method sensitivity. Therefore, increasing extraction time is a way to increase method sensitivity, although we need to stress its potential negative influence on the sample (i.e. fatty acids oxidation processes). 


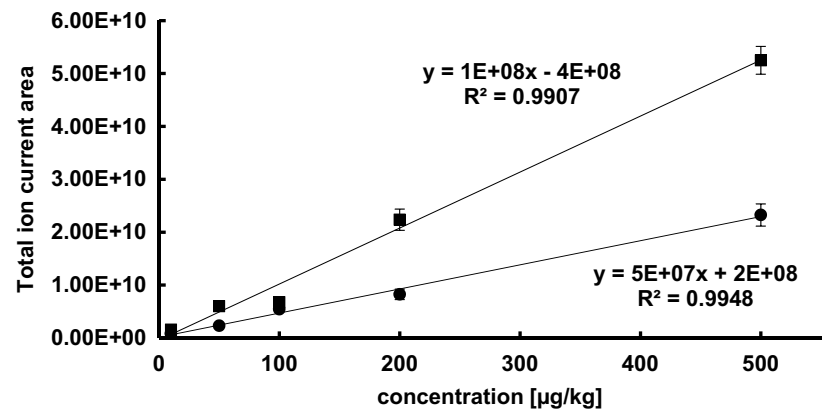

Fig. 3 Total ion current area vs concentration for butanoic acid from water matrix illustrating the influence of extraction time on peak areas. Upper line represents $60 \mathrm{~min}$ Vac-HS-SPME extraction, the lower one represents 15 min Vac-HS-SPME extraction

\section{The effect of temperature}

According to a previous study [23], an increase in temperature during extraction leads to the release of a greater quantity of volatile compounds into the headspace, since the rise in temperature is proportional to the increase in the analyte diffusion coefficient. However, an excessively high temperature may also lead to the undesirable formation of aroma compounds derived from the Maillard reaction, caramelization of sugars or fatty acid oxidation. It may also provoke the degradation of some compounds in the product. In the case of solid food matrices, such as cheese, a high extraction temperature results in their melting, which influences its physical properties in terms of diffusion of analytes into the headspace. Mixing cheese with water or sodium carbonate prevents cheese from melting. In this study, the extraction temperatures in the range of $40-60{ }^{\circ} \mathrm{C}$ were tested. The data show that the temperature increased to $60{ }^{\circ} \mathrm{C}$ results in non-significant sorption changes for 1-pentanol compared to $50{ }^{\circ} \mathrm{C}$, in a lower sorption of butanoic acid compared to 40 and $50{ }^{\circ} \mathrm{C}$, slightly higher sorption of 2.3-butanedione compared to $50{ }^{\circ} \mathrm{C}$ as well as slightly higher sorption of 2-heptanone compared to $50{ }^{\circ} \mathrm{C}$. Therefore, an increase of extraction temperature to $60{ }^{\circ} \mathrm{C}$ had no further significant $(p<0.05)$ positive effect (Fig. 4). For further extraction, the temperature was set to $50{ }^{\circ} \mathrm{C}$. In turn, Mondello et al. in their screening of various grated cheeses suggested $60{ }^{\circ} \mathrm{C}$ as a compromise between equilibrium time and sensitivity, while for testing times between 10 and $80 \mathrm{~min}$ it was decided to apply $50 \mathrm{~min}$ exposure time [20].

\section{The effect of vacuum on extraction of volatiles}

The effect of vacuum on the extraction efficiency of the above-mentioned selected volatile compounds (1-pentanol, butanoic acid, 2,3-butanedione and 2-heptanone)

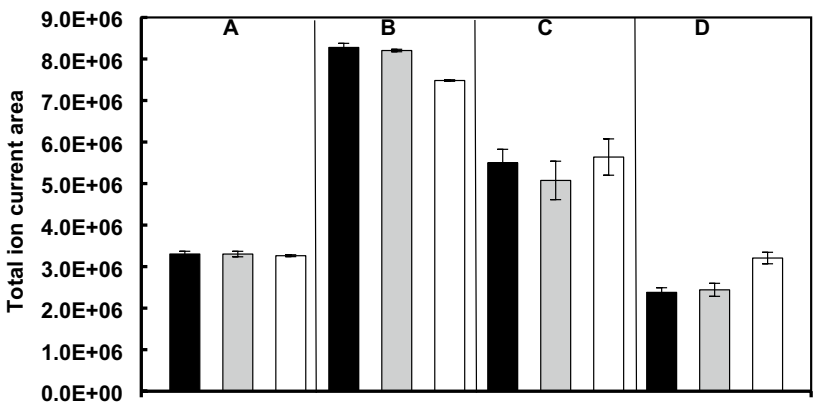

Fig. 4 Distribution of selected volatile compounds for different VacHS-SPME extraction temperatures: $40{ }^{\circ} \mathrm{C}$ (black), $50{ }^{\circ} \mathrm{C}$ (grey), $60{ }^{\circ} \mathrm{C}$ (white); A-1-pentanol; B-butanoic acid; C-2,3-butanedione; D-2-heptanone $(n=3)$

was tested at first in water solutions for various concentrations (from 10 to $1000 \mu \mathrm{g} / \mathrm{kg}$ ), as seen in Fig. 5. The effect of vacuum pressure was the greatest for butanoic acid; however, significant differences $(p<0.05)$ were observed for all the investigated compounds. Their peak areas increased, which agrees with the theory [31], particularly for organic acids, resulting in the nonlinear response for all volatile compounds. When determining these analytes in the water matrix, the linear range of the method would be restricted depending on the compound, as partition of these compounds from water favored their high concentrations in the headspace.

When the mixture (cheese: $\mathrm{Na}_{2} \mathrm{CO}_{3}, 1: 1 \mathrm{w} / \mathrm{w}$ ) was used as a matrix, the influence of vacuum was non-significant $(p<0.05)$ for all the compounds except for butanoic acid (Fig. 6). As can be observed, the greatest positive effect of higher sorption was noted for butanoic acid, with a much less pronounced effect on the other compounds. This illustrates the crucial role of partition coefficients for sampling compounds with SPME and as a result the behavior of compounds may be very different in various matrices. At low concentrations of investigated compounds in the water matrix (Fig. 5), the differences between ambient pressure and vacuum sampling were relatively small (as for butanedione). In the cheese matrix, in which the concentrations (except for butanoic acid) were also relatively low, the differences between vacuum and standard extraction conditions were negligible. Summing up, in the cheese matrix the most significant effect was observed for butanoic acid (Fig. 6), whose concentration was nevertheless very high and it had to be reduced using sodium bicarbonate solution. However, in cases when other short- or mediumchain fatty acids are to be determined in cheese and their concentrations are much lower, the vacuum SPME sampling approach may be the simplest way to improve their detectability. 
Fig. 5 Effect of vacuum (black) and ambient pressure (white) extraction of investigated volatiles from water matrix $(n=3)$
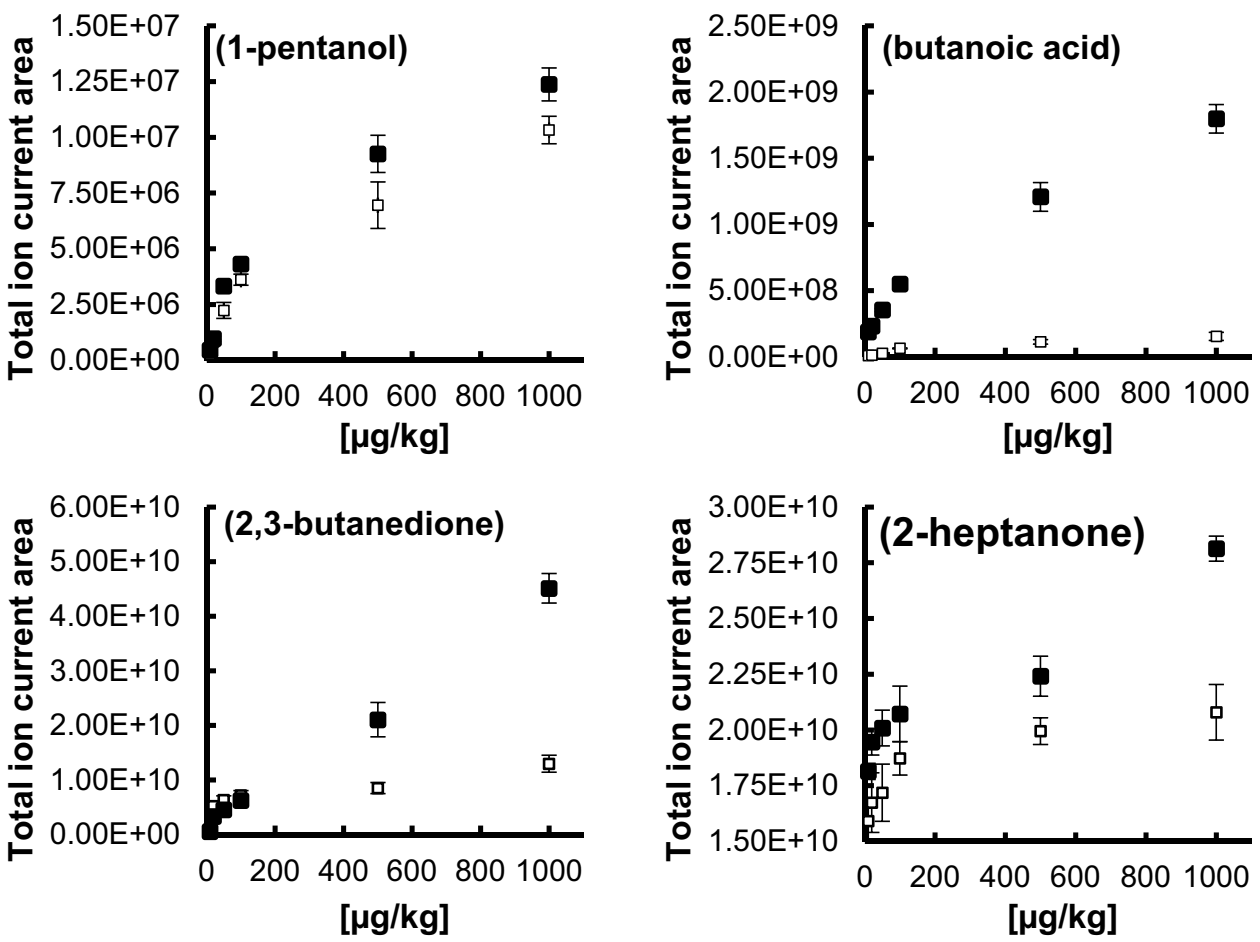

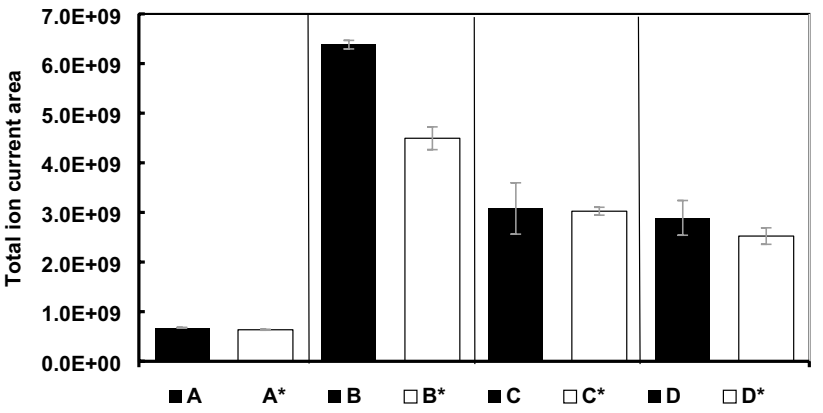

Fig. 6 Comparison of peak areas of investigated compounds in Emmental cheese with standard addition extracted under vacuum (black) and at ambient pressure (white) using HS-SPME; A/A*1-pentanol; B/B*-butanoic acid; $\mathrm{C} / \mathrm{C}^{*}-2,3$-butanedione; $\mathrm{D} / \mathrm{D}^{*}$ 2-heptanone $(n=3)$

\section{Application of the optimized method for cheese samples}

Several samples of semi-hard cheeses such as Edam, Emmentaler, Gouda and Maasdam were purchased at the local store and analyzed by the developed method. Linearity with the highest confidential factor in this range was recorded for butanoic acid $\left(R^{2}=0.9991\right)$, followed by 1-pentanol $\left(R^{2}=0.9984\right), 2$-heptanone $\left(R^{2}=0.9908\right)$ and 2,3-butanedione $\left(R^{2}=0.9670\right)$. Standard curves were adjusted by the subtraction of peak areas for the compounds already present in the Emmental matrix used for calibration and spiked with standards. The results in Table 1 show very good repeatability for selected volatile compounds. Both Gouda and Maasdam samples contained significantly $(p<0.05)$ higher concentrations of 2,3-butanedione (diacetyl) than Edam and Emmentaler cheeses, probably due to the use of different microbiota for metabolic degradation of casein. As predicted, purchased cheese samples are characterized by different concentrations of investigated volatile
Table 1 Comparison of investigated volatile compounds amounts in various semi-hard cheeses by vacuum HS-SPME extraction

\begin{tabular}{lccrr}
\hline Sample & \multicolumn{3}{l}{ Concentration $[\mu \mathrm{g} / \mathrm{kg}]$} & \\
\cline { 2 - 5 } & \multicolumn{1}{l}{ 1-pentanol } & Butanoic acid & 2,3-butanedione & 2-heptanone \\
\hline Gouda & $7.17 \pm 0.08$ & $454.23 \pm 6.76$ & $1596.19 \pm 5.56$ & $4.60 \pm 0.05$ \\
Edam & $37.10 \pm 1.40$ & $149.81 \pm 2.06$ & $45.14 \pm 1.32$ & $4.15 \pm 0.09$ \\
Maasdam & $154.10 \pm 3.25$ & $1981.87 \pm 32.82$ & $2057.01 \pm 36.85$ & $10.01 \pm 0.44$ \\
Emmentaler & $243.77 \pm 18.88$ & $591.66 \pm 23.07$ & $34.08 \pm 0.28$ & $3.61 \pm 0.17$ \\
\hline
\end{tabular}


compounds, as they vary in maturation time, culture usage, exact dry matter and fat content in dry matter.

\section{Conclusions}

This paper investigated the applicability of vacuum during HS-SPME extraction of cheese volatile compounds. The results clearly indicate that the beneficial influence of vacuum on the migration of volatiles into the headspace is different for the compounds examined. Contrary to the release from the water matrix in a model system, in which a significant effect of vacuum was observed for all the examined compounds, their extraction from cheese resulted in a significant influence of vacuum only for butanoic acid. In contrast, it was negligible for the other compounds. In the case of the examined cheeses characterized by high concentrations of butanoic acid, there was no problem with detectability, which would require the use of vacuum. However, in the cheeses, in which short- or medium-chain fatty acids (C2-C8) are present at low concentrations, vacuum applied for SPME sampling may significantly improve their detectability. The Vac-HS-SPME approach when used with the standard addition method for quantitation of compounds of interest provided very good repeatability and a sufficient linear range, while it facilitated a reliable quantitative analysis.

Funding This study was funded by the standard project of specific research no. FCH-S-19-5983.

\section{Compliance with ethical standards}

Conflict of interest The authors declare that they have no conflict of interest.

Ethical approval This article does not contain any studies with human or animal subjects.

Open Access This article is licensed under a Creative Commons Attribution 4.0 International License, which permits use, sharing, adaptation, distribution and reproduction in any medium or format, as long as you give appropriate credit to the original author(s) and the source, provide a link to the Creative Commons licence, and indicate if changes were made. The images or other third party material in this article are included in the article's Creative Commons licence, unless indicated otherwise in a credit line to the material. If material is not included in the article's Creative Commons licence and your intended use is not permitted by statutory regulation or exceeds the permitted use, you will need to obtain permission directly from the copyright holder. To view a copy of this licence, visit http://creativecommons.org/licenses/by/4.0/.

\section{References}

1. Pawliszyn J (1997) Solid phase microextraction. Theory and Practice. Wiley-VCH, Inc, pp 264

2. Ai J (1997) Solid phase microextraction for quantitative analysis in nonequilibrium situations. Anal Chem 69:1230-1236

3. Kataoka H, Lord HL, Pawliszyn J (2000) Applications of solid phase microextraction in food analysis. J Chromatogr A 880:35-62

4. Jeleń H, Majcher M, Dziadas M (2012) Microextraction techniques in the analysis of food flavor compounds: a review. Anal Chim Acta 738:13-26

5. Carasek E, Cudjoe E, Pawliszyn J (2007) Fast and sensitive method to determine chloroanisol in cork using an internally cooled solid-phase microextraction fiber. J Chromatogr A 1138:10-17

6. Krings U, Banavara DS, Berger RG (2003) Thin layer high vacuum distillation to isolate the flavor of high-fat food. Eur Food Res Technol 217:70-73

7. Brunton NP, Cronin DA, Monahan FJ (2001) The effect of temperature and pressure on the performance of carboxen/PDMS fibres during solid phase microextraction (SPME) of headspace volatiles from cooked and raw turkey breast. Flavour Fragr J 16:294-302

8. Psillakis E (2017) Vacuum-assisted headspace solid-phase microextraction: a tutorial review. Anal Chim Acta 986:12-24

9. Psillakis E, Mousouraki A, Yiantzi E, Kalogerakis N (2012) Effect of Henry's law constant and operating parameters on vacuumassisted headspace solid phase microextraction. J Chromatogr A 1244:55-60

10. Yiantzi E, Kalogerakis N, Psillakis E (2016) Design and testing of a new sampler for simplified vacuum-assisted headspace solidphase microextraction. Anal Chim Acta 927:46-54

11. Glykioti M-L, Yiantzi E, Psillakis E (2016) Room temperature determination of earthy-musty odor compounds in water using vacuum assisted headspace solid phase microextraction. Meth Anal. https://doi.org/10.1039/C6AY02210C

12. Trujillo-Rodríguez MJ, Pino V, Psillakis E, Anderson JL, Ayala JH, Yiantzi E, Afonso AM (2017) Vacuum-assisted headspacesolid phase microextraction for determining volatile free fatty acids and phenols. Investigation on the effect of pressure on competitive adsorption phenomena in a multicomponent system. Anal Chim Acta 962:41-51

13. McSweeney PLH (2004) Biochemistry of cheese ripening. Int J Dairy Technol 57(2-3):127-144

14. Fox PF, McSweeney PL, Cogan TM, Guinee TP (eds) (2004) Cheese: chemistry, physics and microbiology, volume 2: major cheese groups. Elsevier, Amsterdam

15. Curioni PMG, Bosset JO (2002) Key odorants in various cheese types as determined by gas chromatography-olfactometry. Int Dairy J 12(12):959-984

16. Ceruti RJ, Zorrilla SE, Sihufe GA (2016) Volatile profile evolution of Reggianito cheese during ripening under different temperaturetime combinations. Eur Food Res Technol 242(8):1369-1378

17. Thierry A, Maillard MB, Le Quéré JL (1999) Dynamic headspace analysis of emmental aqueous phase as a method to quantify changes in volatile flavour compounds during ripening. Int Dairy J 9(7):453-463

18. Rychlik M, Warmke R, Grosch W (1997) Ripening of Emmental cheese wrapped in foil with and without addition of Lactobacillus casei subsp. casei. III. Analysis of character impact flavour compounds. Food Sci Technol 30(5):471-478

19. Preininger M, Grosch W (1994) Evaluation of key odorants of the neutral volatiles of Emmentaler cheese by the calculation of odour activity values. Food Sci Technol 27(3):237-244 
20. Mondello L, Costa R, Tranchid PQ, Chiofalo B, Zumbo A, Dugo P (2005) Determination of flavor components in Sicilian goat cheese by automated HS-SPME-GC. Flavour Frag J 20:659-665

21. Januszkiewicz J, Sabik H, Azarnia S, Lee B (2008) Optimization of headspace solid-phase microextraction for the analysis of specific flavors in enzyme modified and natural cheddar cheese using factorial design and response surface methodology. J Chromatogr A 1195:16-24

22. Bezzera TKA, Araújo ARR, Arcanjo NMDO, da Silva FLH, Queiroga RDCRDE, Madruga MS (2016) Optimization of HSSPME-GC/MS technique for the analysis of volatile compounds in caprine Coalho cheese using response surface methodology. Food Sci Technol 36(1):103-110

23. Wolf IV, Perotti MC, Bernal SM, Zalazar CA (2010) Study of the chemical composition, proteolysis, lipolysis and volatile compounds profile of commercial Reggianito Argentino cheese: characterization of Reggianito Argentino cheese. Food Res Int 43(4):1204-1211

24. Delgado FJ, González-Crespo J, Cava R, Ramírez R (2011) Formation of the aroma of a raw goat milk cheese during maturation analysed by SPME-GC-MS. Food Chem 129:1156-1163

25. Urgeghe PP, Piga C, Addis M, Di Salvo R, Piredda G, Scintu MF, Wolf IV, Sanna G (2011) SPME/GC-MS characterization of the volatile fraction of an Italian PDO sheep cheese to prevalent lypolitic ripening: the case of Fiore Sardo. Food Anal Methods 5:723-730

26. Ziino M, Condurso C, Romeo V, Giuffrida D, Verzera A (2005) Characterization of "Provola dei Nebrodi", a typical Sicilian cheese, by volatiles analysis using SPME-GC/MS. Int Dairy J 15:585-593

27. Rincôn AA, Pino V, Ayala JH, Afonso AM (2014) Multiple headspace solid-phase microextraction for quantifying volatile fatty acids in cheese. Talanta 129:183-190

28. Canac-Arteaga D, Begnaud F, Viallon C, Berdague JL (2000) Effect of adding hygroscopic salts on the analysis of the volatile fraction of cheese. Analysis 28(10):973-979

29. Frank DC, Owen CM, Patterson J (2004) Solid phase microextraction (SPME) combined with gas chromatography and olfactometry-mass spectrometry for characterization of cheese aroma compounds. LWT Food Sci Technol 37:139-154

30. Jeleń HH, Gracka A (2015) Analysis of black pepper volatile compounds by solid phase microextraction-gas chromatography: a comparison of terpenes profiles with hydrodistillation. J Chromatogr A 1418:200-220

31. Psillakis E, Yiantzy E, Sanchez-Prado L, Kalogerakis N (2012) Vacuum-assisted headspace solid phase microextraction: improved extraction of semivolatiles by non-equilibrium headspace sampling under reduced pressure conditions. Anal Chim Acta 742:30-36

Publisher's Note Springer Nature remains neutral with regard to jurisdictional claims in published maps and institutional affiliations. 